\title{
Sildenafil delays the intestinal transit of a liquid meal in awake rats
}

\author{
J.R.V. Graça1, G.M. Macedo1, R.C. Palheta Jr. ${ }^{1}$, F. de A.A. Gondim¹, R.O. Nogueira1, \\ J.M. Correia ${ }^{1}$, F.H. Rola ${ }^{1}$, R.B. Oliveira ${ }^{2}$, M.A.N. Souza ${ }^{1}$ and A.A. Santos ${ }^{1}$ \\ 1'Departamento de Fisiologia e Farmacologia, Faculdade de Medicina, Universidade Federal do Ceará, \\ Fortaleza, CE, Brasil \\ 2Departamento de Clínica Médica, Faculdade de Medicina de Ribeirão Preto, Universidade de São \\ Paulo, Ribeirão Preto, SP, Brasil
}

Correspondence to: A.A. Santos, Laboratório Escola Prof. Luiz Capelo, Departamento de Fisiologia e Farmacologia, Faculdade de Medicina, Universidade Federal do Ceará, 60430-270 Fortaleza, CE, Brasil Fax: +55-85-3366-8333. E-mail: meno@ufc.br

\begin{abstract}
Sildenafil slows down the gastric emptying of a liquid test meal in awake rats and inhibits the contractility of intestinal tissue strips. We studied the acute effects of sildenafil on in vivo intestinal transit in rats. Fasted, male albino rats $(180-220 \mathrm{~g}, \mathrm{~N}=44)$ were treated $(0.2 \mathrm{~mL}, i v)$ with sildenafil $(4 \mathrm{mg} / \mathrm{kg})$ or vehicle $(0.01 \mathrm{~N} \mathrm{HCl})$. Ten minutes later they were fed a liquid test meal ${ }^{99 m}$ technetium-labeled saline) injected directly into the duodenum. Twenty, 30 or 40 min after feeding, the rats were killed and transit throughout the gastrointestinal tract was evaluated by progression of the radiotracer using the geometric center method. The effect of sildenafil on mean arterial pressure (MAP) was monitored in a separate group of rats $(\mathrm{N}=14)$. Data (medians within interquartile ranges) were compared by the Mann-Whitney U-test. The location of the geometric center was significantly more distal in vehicle-treated than in sildenafil-treated rats at 20, 30, and 40 min after test meal instillation (3.3 (3.0-3.6) vs 2.9 (2.7$3.1)$; 3.8 (3.4-4.0) vs 2.9 (2.5-3.1), and 4.3 (3.9-4.5) vs 3.4 (3.2-3.7), respectively; $\mathrm{P}<0.05)$. MAP was unchanged in vehicletreated rats but decreased by $25 \%(P<0.05)$ within 10 min after sildenafil injection. In conclusion, besides transiently decreasing MAP, sildenafil delays the intestinal transit of a liquid test meal in awake rats.
\end{abstract}

Key words: Intestinal transit; Mean arterial pressure; Scintigraphy; Sildenafil

This study is dedicated to the memory of our colleague Dr. D.A.F. Queiroz. Part of a PhD thesis presented by J.R.V. Graça to the Departamento de Fisiologia e Farmacologia, Faculdade de Medicina, Universidade Federal do Ceará, Fortaleza, CE, Brasil.

Research supported by CNPq and FUNCAP. Publication supported by FAPESP.

Received June 12, 2007. Accepted November 22, 2007

Sildenafil citrate belongs to a class of compounds called phosphodiesterase (PDE) inhibitors. PDEs constitute a family of enzymes that hydrolyze cyclic nucleotides (cyclic adenosine monophosphate and cyclic guanosine monophosphate, cGMP) and play a critical role in the modulation of the second messenger pathway (1). Sildenafil citrate is a selective PDE type 5 inhibitor widely used due to its therapeutic efficacy in human erectile dysfunction and pulmonary hypertension. It effectively blocks the PDE 5-mediated hydrolysis of cGMP inside vascular smooth muscle cells, relaxing the arterioles that supply the corpus cavernosum (2) and the lung parenchyma (3).

Sildenafil increases the gastric resistance to injury by non-steroidal anti-inflammatory drugs (4), decreases the distal esophageal peristalsis (5), and inhibits the gastric emptying of test meals both in humans and rats $(6,7)$, and decreases the contractility of isolated duodenal strips (8). Since the gastrointestinal transit rate results from a complex interplay between gastric tonus, distal stomach phasic activity and resistance and propulsion offered by the small intestine (9), we measured the effect of sildenafil on the small bowel intestinal transit of a liquid test meal in awake rats. 
Male albino rats ( $180-220 \mathrm{~g}, \mathrm{~N}=58)$ were obtained from the animal house of our institution. All animal handling and experimental protocols followed the guidelines of the Brazilian College of Animal Experimentation and were approved by local Research Ethics Committee. Rats were initially submitted to $24 \mathrm{~h}$ of fasting in individual Bowman cages. After anesthesia with tribromoethanol $(250 \mathrm{mg} / \mathrm{kg}, i p)$, the cervical vessels were cannulated with a polyethylene catheter (PE 50) filled with saline and heparin (500 units $/ \mathrm{mL}$ ) that was tunneled subcutaneously to the back of the rats and then fixed with a silk ligature between the shoulders. After laparotomy, a silastic tube (6 $\mathrm{mm}$ OD) was inserted through a midgastric incision and its distal end positioned in the proximal duodenum $(\sim 1.0 \mathrm{~cm}$ beyond the pylorus). The tube was fixed to the gastric wall with a pouch suture and its proximal end tunneled subcutaneously to the interscapular region, where it was externalized and occluded. After 3 days of recovery from surgery, the animals were again submitted to fasting for $16 \mathrm{~h}$ with free access to an oral hydration solution ( $75 \mathrm{mM} \mathrm{Na}^{+}, 65 \mathrm{mM} \mathrm{Cl}^{-}, 20 \mathrm{mM} \mathrm{K}^{+}, 75 \mathrm{mM}$ glucose, and $10 \mathrm{mM}$ citrate). All experiments were performed on awake, freely moving rats after a 30-min period for adaptation to the laboratory environment.

First, the rats were randomly treated $(0.2 \mathrm{~mL}, i v)$ with either sildenafil $(4 \mathrm{mg} / \mathrm{kg}, \mathrm{N}=21)$ or vehicle $(0.01 \mathrm{~N} \mathrm{HCl}, \mathrm{N}$ $=23)$. After $10 \mathrm{~min}$, they were fed a liquid test meal $(10 \mathrm{MBq}$ $99 \mathrm{~m}$ technetium coupled to phytate diluted in $1.0 \mathrm{~mL}$ saline) injected via the tube directly into the proximal duodenum. After 20,30 , or $40 \mathrm{~min}$, rats were killed by excess pentobarbital anesthesia and then submitted to gut exeresis. The stomach and the first $1.0 \mathrm{~cm}$ of the proximal duodenum that contained the cannula comprised segment 1 . The remaining intestine was carefully removed and slightly stretched. Obstructive ligatures were performed to obtain five consecutive segments of the small bowel (about $20 \mathrm{~cm}$ long) whereas the entire large bowel comprised segment 7 . Radioactivity was determined with a $\gamma$-camera (Millennium MPR, General Electrics Inc., USA) in each segment. Data were recorded by the Solaris 2.0 computer system (SUN Microsystems Inc., USA) as number of counts per minute, after discounting background activity. To rule out eventual gut absorption of the marker, carcass radioactivity was also obtained. Fractional marker retention was calculated for each gut segment as a ratio between the counts obtained in this segment and the sum of counts of all gastrointestinal segments, including the gastroduodenal one. The data obtained for each individual segment were then multiplied by the number of the respective segment and summed up to calculate the geometric center of the marker distribution throughout the gastrointestinal tract (10).

Next, the rats were connected to a transducer coupled to a data acquisition system (PowerLab ${ }^{\circledR}$; $A D$ Instruments, Australia). After a 30-min period of stabilization, mean arterial pressure (MAP, in $\mathrm{mmHg}$ ) was continuously recorded on a microcomputer for $1 \mathrm{~h}$. The first 20 min were considered as a basal period. Next, the rats were randomly treated $(0.2 \mathrm{~mL}, i v)$ with sildenafil $(4 \mathrm{mg} / \mathrm{kg}, \mathrm{N}=8)$ or vehicle $(0.01 \mathrm{~N} \mathrm{HCl}, \mathrm{N}=6)$, as described before. MAP values obtained after vehicle or sildenafil treatment were pooled into consecutive 10-min intervals.

Intestinal transit indexes were compared by the MannWhitney U-test and are reported as medians within interquartile ranges. Differences between MAP values are reported as mean \pm SEM and were compared by one-way ANOVA for repeated measures and the Bonferroni test. $P$ values lower than 0.05 were considered to be statistically significant.

Typical scintiscans of the intestinal transit obtained from vehicle- and sildenafil-treated rats studied $40 \mathrm{~min}$ after meal gavage are shown in Figure 1A. On the sildenafil scintiscan, one can see that the foremost marker retention in proximal gut segments ( 2 and 3 ) was well behind when compared to that obtained on the placebo scintiscan. In both groups, there was also radioactive marker retention in segment 1 (corresponding to the stomach and duodenal stump), probably due to duodenogastric reflux after intraduodenal administration.

Figure 1B shows that sildenafil treatment induced a consistent delay in intestinal transit. In the control group, the radioactive marker progressed throughout the gastrointestinal tract; i.e., the center of mass advanced gradually over 20,30 , and $40 \mathrm{~min}$ after the meal (3.3 (3.0-3.6), $3.8(3.4-4.0)$, and $4.3(3.9-4.5))$, respectively. On the other hand, the center of mass of the sildenafil-treated animals remained behind, i.e., 2.9 (2.7-3.1); 2.9 (2.5-3.1) and 3.4 (3.2-3.7), respectively at 20,30 , and $40 \mathrm{~min}$ after the meal $(P<0.05)$.

Table 1 compares the effects of sildenafil or vehicle treatment on the MAP of awake rats. In control rats, MAP remained within stable levels $(P<0.05)$ throughout the experiments $(96.0 \pm 3.5,95.2 \pm 3.4,90.1 \pm 3.0,98.0 \pm 3.2$, $97.4 \pm 3.6,98.0 \pm 3.0 \mathrm{mmHg}$, respectively for basal, vehicle injection, gavage feeding, and 20-, 30-, and 40-min postprandial intervals). On the other hand, sildenafil treatment induced a significant but short-lived arterial hypotension (a $25 \%$ drop at nadir) from the respective basal MAP values $(100.2 \pm 3.0 \mathrm{mmHg})$. After gavage there was only a residual decrease $(P<0.05)$ in MAP in sildenafil-treated rats $(85.9 \pm 1.8 \mathrm{mmHg})$, with MAP reaching levels similar to basal ones thereafter $(96.2 \pm 3.0,97.3 \pm 3.5$, and $98.2 \pm 3.0$ $\mathrm{mmHg}$, respectively for the $20-, 30-$, and 40 -min postprandial intervals). 
In the present investigation, intestinal transit was studied by scintigraphy, which allows the determination of the fractional retention of a radioactive marker throughout the gastrointestinal tract. This method has been extensively employed due to its simplicity, ease-of-use, and accuracy (11). The present indexes of intestinal transit obtained from control rats were quite similar to those reported by others (10).

In the present study, we observed that sildenafil reduces the intestinal transit of a radioactive liquid test meal directly injected into the duodenum of awake rats.

The remarkable retention of an isotope marker in the proximal gut segments and the delayed intestinal transit in sildenafil-treated rats could be due to intestinal myorelaxation or increased segment contractions (12). We have previously reported that sildenafil inhibits both spontane-

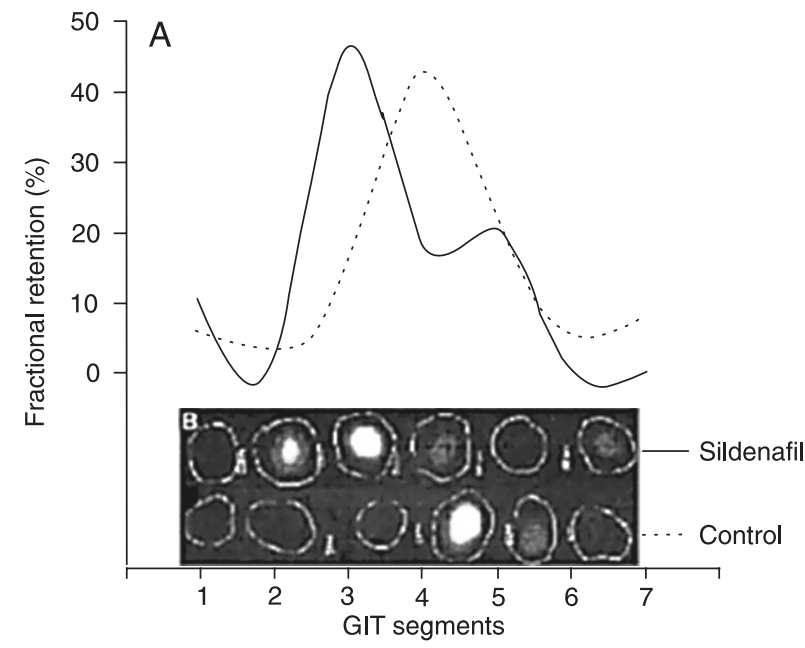

ous and cholinergic-induced duodenal contractions (8). In the same direction, drugs that inhibit gut contractility, such as opioids, delay the intestinal transit of test meals in awake animals $(13,14)$. Since gastrointestinal smooth muscle cells also exhibit the PDE type 5 enzyme (15), the increase in intracellular levels of cGMP presumably caused by sildenafil could have induced myorelaxation that delayed the intestinal transit. The present data agree with previous reports of a gastrointestinal transit delay induced by sildenafil both in humans and animals $(7,16)$. Since sildenafil crosses the blood brain barrier, this drug can also act on the central nervous system (17). Thus, one cannot rule out the possibility that the sildenafil-associated intestinal transit delay could be secondary to a sympathetic nervous system activation promoted by the drug $(7,18)$.

As previously demonstrated (19), sildenafil induced

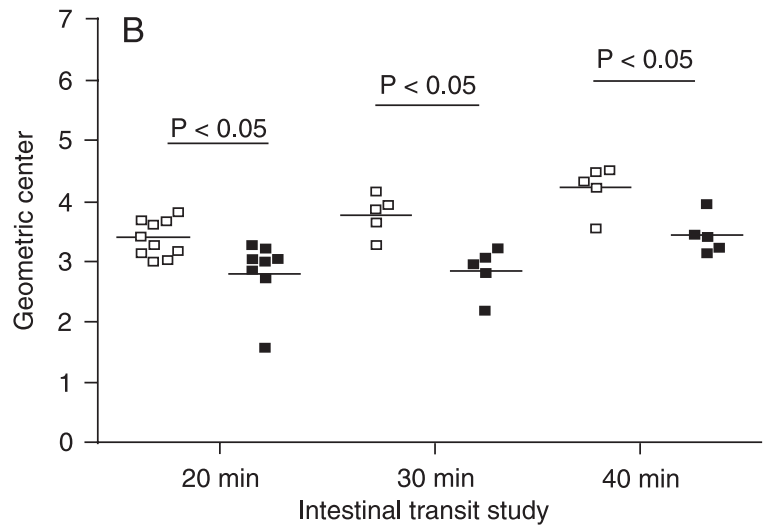

Figure 1. Comparison of iv treatment $(0.2 \mathrm{~mL})$ with sildenafil $(4 \mathrm{mg} / \mathrm{kg})$ or vehicle $(0.01 \mathrm{~N} \mathrm{HCl})$ on the intestinal transit of a liquid test meal in awake rats. Ten minutes after treatment, rats were fed by intraduodenal injection a 1.0-mL bolus of saline labeled with

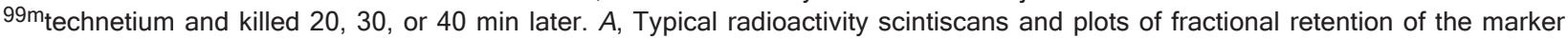
throughout the gut, from the stomach and proximal duodenum (segment number 1) to the large bowel (segment number 7) of sildenafil- (full line) or vehicle (broken line)-treated rats, studied at $40 \mathrm{~min}$ after the meal. GIT = gastrointestinal tract. $B$, Values of the geometric center of radioactivity distribution from the stomach and proximal duodenum (segment number 1) to the large bowel (segment number 7) of awake rats treated with sildenafil (filled squares) or vehicle (open squares). Horizontal bars are medians. P < 0.05 compared to control (Mann-Whitney U-test).

Table 1. Effects of $i v$ treatment $(0.2 \mathrm{~mL})$ withsildenafil $(4 \mathrm{mg} / \mathrm{kg})$ or vehicle $(0.01 \mathrm{~N} \mathrm{HCl})$ on the mean arterial pressure (MAP, $\mathrm{mmHg}$ ) of awake rats.

\begin{tabular}{|c|c|c|c|c|c|c|}
\hline Treatment & Basal & Injection & Gavage & $20 \mathrm{~min}$ & $30 \mathrm{~min}$ & $40 \mathrm{~min}$ \\
\hline Vehicle $(N=6)$ & $96.0 \pm 3.5$ & $95.2 \pm 3.4$ & $90.1 \pm 3.0$ & $98.0 \pm 3.2$ & $97.4 \pm 3.6$ & $98.0 \pm 3.0$ \\
\hline Sildenafil $(\mathrm{N}=8)$ & $100.2 \pm 3.0$ & $75.0 \pm 3.0^{*}$ & $85.9 \pm 1.8^{*}$ & $96.2 \pm 3.0$ & $97.3 \pm 3.5$ & $98.2 \pm 3.0$ \\
\hline
\end{tabular}

Data are reported as means \pm SEM.

${ }^{*} \mathrm{P}<0.05$ (ANOVA and Bonferroni's test). 
arterial hypotension. However, this effect was short-lived compared to the delay of intestinal transit, which persisted for at least $50 \mathrm{~min}$ after drug administration. Thus, it seems that the sildenafil-induced delay of the intestinal transit results from a direct action of the drug on the gastrointestinal smooth muscle cells, instead of a secondary hemodynamic effect (19). Interestingly, there was almost no retention of the isotope marker in the gastroduodenal stumps of the sildenafil-treated rats. We wonder if this phenomenon could be related to a greater intestinal compliance induced by sildenafil, decreasing the duodenogastric reflux.

Sildenafil transiently decreases MAP and delays the intestinal transit of a liquid test meal in awake rats. The slowing down of both gastric emptying and intestinal transit induced by sildenafil could be related to the side effects of the drug since as many as $3 \%$ of sildenafil users have reported gut dysmotility complaints such as dyspepsia and diarrhea (20).

\section{ACKNOWLEDGEMENTS}

The authors wish to thank Mr. Haroldo Pinheiro for excellent technical assistance.

\section{REFERENCES}

1. Gibson A. Phosphodiesterase 5 inhibitors and nitrergic transmission - from zaprinast to sildenafil. Eur J Pharmacol 2001; 411: 1-10.

2. Goldstein I, Lue TF, Padma-Nathan H, Rosen RC, Steers WD, Wicker PA. Oral sildenafil in the treatment of erectile dysfunction. Sildenafil Study Group. N Engl J Med 1998; 338: 1397-1404.

3. Barreto AC, Franchi SM, Castro CR, Lopes AA. One-year follow-up of the effects of sildenafil on pulmonary arterial hypertension and veno-occlusive disease. Braz J Med Biol Res 2005; 38: 185-195.

4. Santos CL, Souza MH, Gomes AS, Lemos HP, Santos AA, Cunha $F Q$, et al. Sildenafil prevents indomethacin-induced gastropathy in rats: role of leukocyte adherence and gastric blood flow. Br J Pharmacol 2005; 146: 481-486.

5. Zhang X, Tack J, Janssens J, Sifrim DA. Effect of sildenafil, a phosphodiesterase-5 inhibitor, on oesophageal peristalsis and lower oesophageal sphincter function in cats. Neurogastroenterol Motil 2001; 13: 325-331.

6. Sarnelli G, Sifrim D, Janssens J, Tack J. Influence of sildenafil on gastric sensorimotor function in humans. Am $J$ Physiol Gastrointest Liver Physiol 2004; 287: G988-G992.

7. de Rosalmeida MC, Saraiva LD, da Graça JR, Ivo BB, da Nobrega MV, Gondim FA, et al. Sildenafil, a phosphodiesterase- 5 inhibitor, delays gastric emptying and gastrointestinal transit of liquid in awake rats. Dig Dis Sci 2003; 48: 2064-2068.

8. Araujo PV, Clemente CM, da Graça JR, Rola FH, de Oliveira $R B$, dos Santos AA, et al. Inhibitory effect of sildenafil on rat duodenal contractility in vitro: putative cGMP involvement. Clin Exp Pharmacol Physiol 2005; 32: 191-195.

9. Malagelada JR, Aspiroz F. Determinants of gastric empty- ing and transit in the small intestine. In: Wood JD (Editor), Handbook of physiology. The gastro-intestinal system. Section VI, Volume 1, Part 2. Bethesda: American Physiological Society; 1989. p 909-937.

10. Troncon LE, Santos AA, Garbacio VL, Secaf M, Verceze AV, Cunha-Melo JR. Inhibition of gastric emptying and intestinal transit in anesthetized rats by a Tityus serrulatus scorpion toxin. Braz J Med Biol Res 2000; 33: 1053-1058.

11. Miller MS, Galligan JJ, Burks TF. Accurate measurement of intestinal transit in the rat. J Pharmacol Methods 1981; 6: 211-217.

12. Lin HC, Prather C, Fisher RS, Meyer JH, Summers RW, Pimentel $\mathrm{M}$, et al. Measurement of gastrointestinal transit. Dig Dis Sci 2005; 50: 989-1004.

13. Manara L, Bianchi G, Ferretti $P$, Tavani A. Inhibition of gastrointestinal transit by morphine in rats results primarily from direct drug action on gut opioid sites. J Pharmacol Exp Ther 1986; 237: 945-949.

14. Pol O, Valle L, Sanchez-Blazquez P, Garzon J, Puig MM. Antibodies and antisense oligodeoxynucleotides to muopioid receptors, selectively block the effects of mu-opioid agonists on intestinal transit and permeability in mice. $\mathrm{Br} \mathrm{J}$ Pharmacol 1999; 127: 397-404.

15. Kaneda T, Yamamoto H, Azegami Y, Shimizu K, Urakawa $\mathrm{N}$, Nakajyo S. Lack of cyclic nucleotide regulation of MBCQinduced relaxation of rat ileal smooth muscle. J Smooth Muscle Res 2003; 39: 47-54.

16. Bortolotti M, Mari C, Lopilato C, La Rovere L, Miglioli M. Sildenafil inhibits gastroduodenal motility. Aliment Pharmacol Ther 2001; 15: 157-161.

17. Vobig MA. Retinal side-effects of sildenafil. Lancet 1999; 353: 1442.

18. Phillips BG, Kato M, Pesek CA, Winnicki M, Narkiewicz K, Davison D, et al. Sympathetic activation by sildenafil. Circulation 2000; 102: 3068-3073.

19. Gondim FA, de-Oliveira GR, Graça JR, Cavalcante DI, Souza MA, Santos AA, et al. Variations in gastric emptying of liquid elicited by acute blood volume changes in awake rats. Braz J Med Biol Res 1998; 31: 967-973.

20. Goldenberg MM. Safety and efficacy of sildenafil citrate in the treatment of male erectile dysfunction. Clin Ther 1998; 20: $1033-1048$. 